\title{
Topological Properties of China Input-Output Networks
}

\author{
Ge Zhiyuan*, Hou Jie \\ School of Economics and Management, Beijing University of Technology, China
}

Copyright $\bigcirc 2018$ by authors, all rights reserved. Authors agree that this article remains permanently open access under the terms of the Creative Commons Attribution License 4.0 International License

\begin{abstract}
The aim of this paper is to contribute to a better understanding of developments and changes of China economy from the perspective of input-output networks between 1990 and 2013. Through choosing a network-based approach and combining this with input-output data we are able to analyze the changes and evolutions of centralities, which measured by strength centrality and clustering coefficient, and some extend measures based on centrality including import penetration, international outsourcing and distance to final demand. Our findings show that the basic impression about China input-output networks is that flows are concentrated on some minority points, and also concentrated on the diagonal line obviously, and the self-inputs by industries are normal and significant. Moreover, during recent years the trend of lower and wider peak of the density strength centrality curves illustrates the more balance of China economy than at the beginning of this century, and construction has always been the pillar industry. The changes of distribution of import penetration have been flatter and lower since 1990 and then narrower and higher about after 2001. This trend means that after 2001 most of China industries decrease the dependencies of import from outside. Some trade pattern in measures of distance to final demand and clustering coefficient are exhibited in this paper.
\end{abstract}

Keywords Complex Networks, China Input-Output Table, Centrality Analysis, Distance to Final Demand

\section{Introduction}

Complex networks can be used to characterize a series of different systems where multiple agents (nodes) interact with each other through their relationships (edges) (Newman 2003). This approach has provided new insights in understanding complex phenomena in various fields ranging from biology to economics and finance (Cerina et al. 2015). National economies which composed of a large number of heterogeneous industries with adaptively trading interactions are typically complex systems (Duan 2011). From this perspective, the ION (Input-Output Networks) system can be regarded as a network where the nodes are the individual industries and the edges are the monetary goods flows between industries. The direction of the flows goes from the seller industry to the buyer industry. Therefore, the economic system can be studied with network views. ION has been analyzed as both binary and weighted, as well as directed and undirected complex network.

As a specific network, the ION has the following features (Cerina, Zhu, et al. 2015): 1) It is directed and weighted, i.e., an industry can act as both a seller and a buyer at the same time and the monetary goods flows between industries vary considerably in volume; 2) It is much denser within the same economy than across economies, i.e., despite the continuously integrated global economy, most economic transactions still happen within the county border. In contrast, due to the low-digit industry classification, the input-output networks at the national level are typically dense and complete; 3 ) It is with strong self-loops, i.e., an industry can acquire a significant amount of inputs from itself, which is again due to the aggregated industry classification.

Taking into account this kind of networks, many studies focused on the static analysis of network features. Cerina et al. (2015) had analyzed world input-output network from global level and regional level based on WIOD database. Maluck and Donner (2015) also built global trade model in network of network perspective. By defined a measure of the dynamic importance of node in ION, Duan analyzed the evolution of node dynamic importance. Iapadre and Tajoli (2015) compared the network centrality properties of emerging countries. Benedicties and Tajoli (2011) modeled the world trade network and analyzed the properties of the trade network, and countries' position in the network.

These studies model economies as input-output networks using economic input-output models, and focus on the world input-output network and paid attention to the properties of network. However, for a big country level economy like China, what roles do specific industrial 
sectors play in the ION? What kind of inter-industrial corporations hold dominant position on an economy scale? What's the evolution tendency of network patterns? How do industries have flow relationships reorganized after economic crisis or critical event in the world?

In our works we illustrate that analyses of NIO tables by means of complex network theory offer meaningful techniques to address these questions. By modelling the China Input-Output networks from 1990 to 2013, the changes and evolutions of network node properties are analyzed. By decomposing the total outputs of industries we explore the demand structure of top industries, and extend measures based on centralities are used to uncover the patterns of specific industries at current stage.

This paper we start with a discussion on the methods and data handling and related preparatory work in section two. In section three we give a description of the properties of China's Input-Output Networks (CION), including node centralities, clustering coefficients, and then reports the empirical results of some measures based on centralities including distance to final demand, import penetration and international outsourcing.

\section{Materials and Methods}

\subsection{Construction of the China Input-Output Networks}

Input-Output data describe an economy as a set of industries (i.e., nodes in IO networks) connected by inter-industrial product flows (i.e., links in IO networks). Table 1 shows the basic overall structure of an input-output table. An industry uses products from other industries for its production, and then provides its products to satisfy final demand and the production of other industries. Value added is created during the production of this industry. Final demand means the amount of products being directly consumed by final uses (i.e., household consumption, government expenditure, fixed capital formation, inventory changes, and exports). Value added is the net additions to the wealth of an economy (i.e., employee compensation, depreciation of fixed assets, net tax on production, and net operating surplus).

Table 1. Overall structure of an input-output framework.

\begin{tabular}{|c|c|c|c|}
\hline & Industries & $\begin{array}{c}\text { Final } \\
\text { Demand }\end{array}$ & Total output \\
\hline Industries & $\begin{array}{c}\text { Technology matrix A } \\
\text { (industry-by-industry }\end{array}$ & $\begin{array}{c}\text { Industry } \\
\text { final } \\
\text { demand } y\end{array}$ & $\begin{array}{c}\text { Industry } \\
\text { output } \mathrm{x}\end{array}$ \\
\hline Value added & Value added $\mathrm{v}$ & & \\
\hline Total output & Industry output $\mathrm{x}$ & & \\
\hline
\end{tabular}

The basic concept for constructing China Input-Output networks is an edge-weighted directed graph $G$. A directed graph consists of a pair $(V, X)$ where $V$ is a finite and non-empty set of elements $i, h$ called nodes and $X$ is a finite set of elements $e_{i h}$ called edges, with $i, h=1, \ldots, k$. An edge-weighted directed graph is described by two function $f_{1,} f_{2}: x \rightarrow V$ and to each $e_{i h} \in X$ finally a weight $w_{i h}>0$ is assigned.

Figure 1 uses a three-industry example to illustrate product flows among industries within an economy, and figure 1 provides a topological view of table 1 . The left side is value added source vector of industries, and the right is final demand destination vector. The edges are with arrows indicating the directions of the monetary goods flows (actually, the flows from the red nodes to the blue nodes are primary inputs) and with varying widths indicating the magnitudes of the flows. Product flows among industries are named intermediate flows. Intermediate flows of an industry includes its intermediate inputs (i.e., product inputs from itself and other industries) and its intermediate outputs (i.e., products allocated to the production of itself and other industries). For a particular industry, the sum of its intermediate outputs and final demand equals to its total output, and the sum of its intermediate inputs and value added equals to its total input. Moreover, an industry's total output equals to its total input.

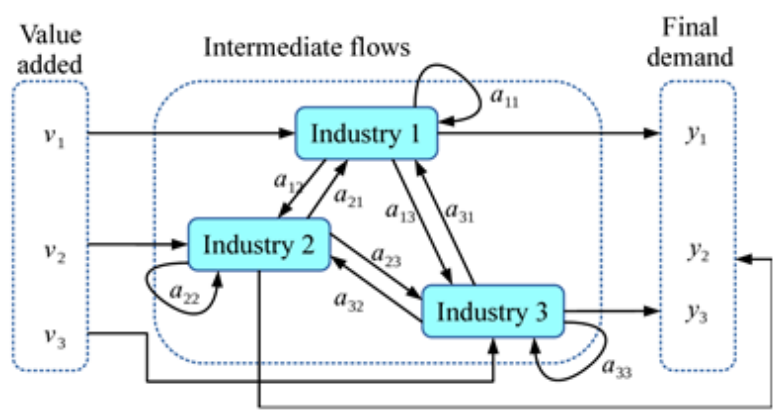

Figure 1. A hypothetical three-industry Input-Output Network. This is a topological view of table 1 . Product flows among industries, and the edges describe the flow relationship, which with arrows indicating the direction of monetary goods flows and with weights indicating the magnitudes of the flows. Because we are only concerned with the inter-industrial input-output relationships, we focus our attention on the network among intermediate flows.

The fundamental equation of the Leontief model (consisting of $\mathrm{N}$ economic sectors) links an exogenous $N \times 1$ final demand vector $y$ with an $N \times 1$ total output vector $x$ via

$$
x=(I-A)^{-1} y=L y
$$

where $A$ is an $N \times N$ matrix of sector intermediate purchases (or direct requirements matrix), $I$ is the $N \times N$ identity matrix, and $L$ is the $N \times N$ Leontief inverse (or total requirements matrix). 


\subsection{Strength Centrality}

Node degree and node strength. We use three indicators including intermediate total demand, industrial total outputs, industrial final demands, and industrial value added to measure node strengths.

As mentioned above, generally CION is a complete network which each element in adjacent matrix of IO table is positive, i.e., there is an edge between any pair of nodes. Therefore, as an undirected and unweighted network, all nodes have degree

Consequently node strength has generally been the basic measure indicator when analyzing weighted networks. This measure has been formalized as follows:

$$
s_{i}=\sum \omega_{i j}
$$

where $\omega$ is the weighted adjacency matrix, in which $\omega_{i j}$ is greater than 0 if the node $i$ is connected to node $j$, and the value represents the weight of edge.

As the adjacency matrix are not symmetric, in-strength centrality identifies the position of an industry $i$ according to the volume directly embodied in intermediate purchases and primary inputs, whereas out-strength centrality directly embodied in intermediate demand and final demand. In-strength and out-strength centralities are defined by:

$$
s_{i}^{\text {in }}=\sum_{j}^{N} \omega_{i j}, \quad s_{i}^{\text {out }}=\sum_{j}^{N} \omega_{j i}
$$

From the global view of IO table, the extend table which combined adjacency matrix and final demand, in-strength centrality is equal to the out-strength centrality. However, to distinguish the features between subnetworks of intermediate nodes and global network, in-strength and out-strength are useful measures.

The closeness and betweenness centrality measures rely on the identification and length of the shortest paths among nodes in the network. Closeness centrality relies on the length of the paths from a node to all other nodes in the network, and is defined as the inverse total length. Betweenness relies on the identification of the shortest paths, and measures the number of them that passes through a node. Generally, the weights are considered as costs of links that high values represented weak or costly edges, whereas low values represented strong or cheap weights (Opsahl 2010). However, in our input-output networks the weights of links are the flows of goods from one node to another, and the shortest path reflects minimal flow between vertexes instead of low cost. Therefore, closeness and betweenness centralities are not suitable for Input-Output Networks.

\subsection{Clustering Coefficient}

The clustering coefficient captures the degree to which the neighbours of a given node link to each other. For directed weighted networks the local clustering coefficient measures the probability of the existence of a link between two randomly selected neighbours of node $i$.

The topological clustering coefficient measures the local group cohesiveness and is defined for any vertex $i$ as the fraction of connected neighbours of $i$. It therefore does not take into account the fact that some neighbours are more important than others. In order to solve this incongruity, it is possible to introduce different definitions of clustering coefficient that explicitly consider the weights of the links and combines the topological information with the weight distribution of the network (Newman 2003).

We use the definition by Alain Barrat (2004) which is a local vertex-level quantity, and its formula is:

$$
C_{i}^{w}=\frac{1}{s_{i}\left(k_{i}-1\right)} \sum_{j, h} \frac{w_{i j}+w_{i h}}{2} a_{i j} a_{i h} a_{j h}
$$

where $s_{i}$ is the strength of vertex $i, a_{i j}$ are elements of the adjacency matrix, $k_{i}$ is the vertex degree, $w_{i j}$ are the weights. This formula does not work for graphs with multiple and/or loop edges, so in our networks the loop flows in the adjacent matrix are ignored.

According to the definition by Barrat et al. (2004), weighted clustering coefficient shows that how closely the subnet which consists of vertex and its neighbourhood is. The more $C_{i}^{w}$ is, the more closely the subnet is. If the local clustering coefficient is high, the industry processes strong local impacts in the sub-network. The clustering coefficient allows to assess directionality patterns and to find characteristic roles of sectors in the supply chain (Maluck, 2015).

\subsection{Strength Centrality-based Measures}

There are some centrality-based measures which express the economic interpretation of node, including distance to final demand, import penetration, and international outsourcing.

To obtain information on the degree to which a single industry $i$ is integrated in the network with respect to vertical interaction with adjacent nodes, we calculate a centrality coefficient, which from an economic viewpoint enables us to identify the import content, the degree of 'import penetration', which defined as the ration of imports of goods and services to total demand for goods and service, introduced by De Backer and Yamano (2008). Here we use the definition similar to the measure defined by Schütz and Palan (2016):

$$
c_{i}^{p}=\frac{s_{i}^{\text {in }, f}}{\left(s_{i}^{\text {in }, f}+s_{i}^{\text {out }, d}\right)}
$$

where $s_{i}^{\text {in, } f}$ denotes the total imports of industry $i$, and $s_{i}^{\text {out }, d}$ corresponds to the domestic total outputs of 
industry $i$. It should be noted that there are variants of this definition, such as the penetration of imports as a proportion of total domestic final demand.

The higher the centrality coefficient, the lower the degree to which a single industrial domestic absorption is satisfied by domestic and vice versa, the more independent it is on industrial imports with respect to directly embodied.

Another centrality coefficient used to evaluate the degree of outsourcing of industries is international outsourcing. There are two kinds of definition of international outsourcing, which are the so-called broad and narrow measure (Falk 2012). The broad outsourcing is given by the following:

$$
c_{i}^{I O}=\frac{s_{i}^{\text {in }, f}}{s_{i}^{\text {in }}}
$$

where shows the volume of industry $i$ directly embodied in intermediate demand flows, including those of a domestic and foreign origin. This measure uses the imported inputs from all industries, while the narrow definition is defined by the ratio of imported intermediates from the same industry to the industry's output.

We use the broad definition of international outsourcing as it is thought to come closer to the essence of fragmentation which necessarily takes place within industry. The higher the international outsourcing, the higher is the industry dependence on foreign production activities.

\section{Distance to final demand}

In a final step, we investigate a structure pattern with respect to the distance to final demand for commodities which against the proximity to intermediate demand. For defining proximity with respect to the final demand sector or intermediate demand sector, we use the economic space as the domain. To derive our measure, we use only partial out-strength centralities. To measure the distance to final demand, the ratio of intermediate demand to final demand is introduced:

$$
d_{f}=\frac{s_{z i}^{o u t}}{s_{f i}^{\text {out }}}
$$

where $s_{z i}^{\text {out }}$ is the intermediate demand for industry $i$, and $s_{f i}^{\text {out }}$ is the final demand of industry $i$. Figure 2 summarizes the criteria for determining the distance to final demand.

For a single industry if $s_{z i}^{\text {out }} / s_{f i}^{\text {out }}>1$ then a relatively larger proportion of its flows is directed toward the intermediate demand sector than to final demand, which means this industry is expected to be closer to the production of intermediate demand than to final demand. On the contrary, if $s_{z i}^{\text {out }} / s_{f i}^{\text {out }} \leq 1$ and hence, industrial outflows are to a larger extent final demand goods then distance to final demand is smaller than to intermediate demand. The higher the distance to final demand, the more an industry is involved in production activities which are located upstream; whereas the closer an industry is to final demand the more it is specialized on downstream production activities.

Changes in values of partial out-strength centralities over time then indicate shifts in the distance to final demand: if the gap to final demand shrinks then an industry moves into a downstream direction, and vice versa this indicates a move into an upstream direction.

\subsection{Data}

Our construction of CION is based on the EORA multi-region input-output table (MRIO) database (Lenzen et al. 2012; Lenzen et al. 2013). Its main advantage over WIOD database is that Eora provides a time series of high resolution IO tables with matching environmental and social satellite accounts, and continuous coverage for the period from 1970 to 2013 at the time of writing while WIOD dataset only cover data for the period from 2000.

This study not considers the development stage of China economy from 1970 to 1980 because during that time China government still not fully focus economic growth. The growth of China economy increased rapidly since 1990 , and most of time it is the fastest growing economy in the world. Furthermore, before 1990 the economy of China was smaller and much more volatile, and still was in a stage of shifting from planned economy to market economy. Based on this background we consider the situation after 1990 in our studies.

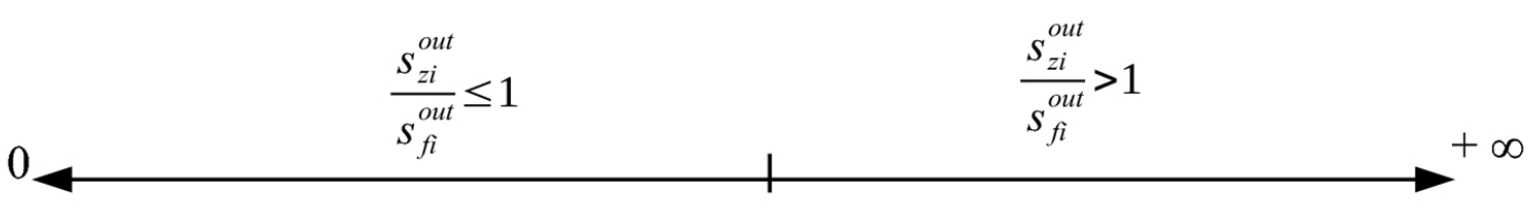

Figure 2. Criteria for determining a single industry's distance to final demand 
Generally, all of data in input-output table are positive, especially for intermediate coefficient. However, in Eora database there are some negative number sometimes in China input-output table, for example the primary inputs and a few of final demand items of some industries, which were the consequences of inventory changes, and this phenomenon has not happen in intermediate matrix. However, in WIOD dataset, even in intermediate matrix there are still a few negative numbers, and it is difficult to explain in physical world. Negative numbers are hard to interpret in building network model and cannot deal with this case. This is another advantage of EORA database comparing with WIOD.

There are 123 commodities in China input-output table in EORA database, and 6 final columns, 6 primary inputs rows, 190 exports and import countries. Consequently, in our network model, China input-output networks shown as figure 1 have 123 intermediate nodes, 191 final demand nodes (domestic final demand node and 190 export nodes) and 191 input nodes (1 primary input node and 190 import nodes).

\section{Analysis and Results}

\subsection{Modelling of China Input-output Networks}

The original data of input-output table like shown in Table 1 can be regarded as flows from one node to another node. Because of fast growth of China economy during last decades, they changed significantly from year to year. If these flows between nodes are treated as the weight of edges in the network model, they just increase continuously over time, and cannot give clear description of the historical changing of CION topological properties. Our analyses focus on the comparison of networks' topological properties, and want to find the tendency over time since 1990, so these data need to be normalized.

In our works we built input-output network models in three ways. The first is based on physical-value input-output table. Just as we mentioned before, because of rapid economic growth during last decades in China, the physical-values in the input-output table expanded a lot each year, and are unsuitable for analyses of topological differences over time. In the second way, our model is built by technical coefficient matrix. Technical coefficients reflect the direct effects of change in final demand for a certain commodity, and be values between 0 and 1 . Therefore, networks model based on technical coefficient are comparable over time. The third way is to normalize the physical value in IO table which use the relative value of each year so that the topological properties are comparable in historical dimension. The simplest way dealing with data is normalized by the method which each item is relative to the maximum value in the table, for example, the maximum value in the intermediate matrix is scaled to be
100 , and other flows are the ratio to this maximum. Thus the properties of each network model have the same scale in which differences among years can be analyzed.

To get a general impression of China input-output networks, we display the industrial product flows in the economy with three-dimensional figures according to the technical coefficient matrix. To compare the changes of China economy, we select four points in time: 2013 the recent year available for data, and then earlier time points each five years 2008, 2003, 1998. To make comparison of these years, we use the normalized technical coefficient matrix as product flows to reflect the relationship between industries with the third way just mentioned in the former paragraph. Figure 3 shows the results of this idea from overall product flows perspective. The bottom facet represents the relationship from industries to industries in the input-output table, and the vertical coordinate represents the value flows between industries.

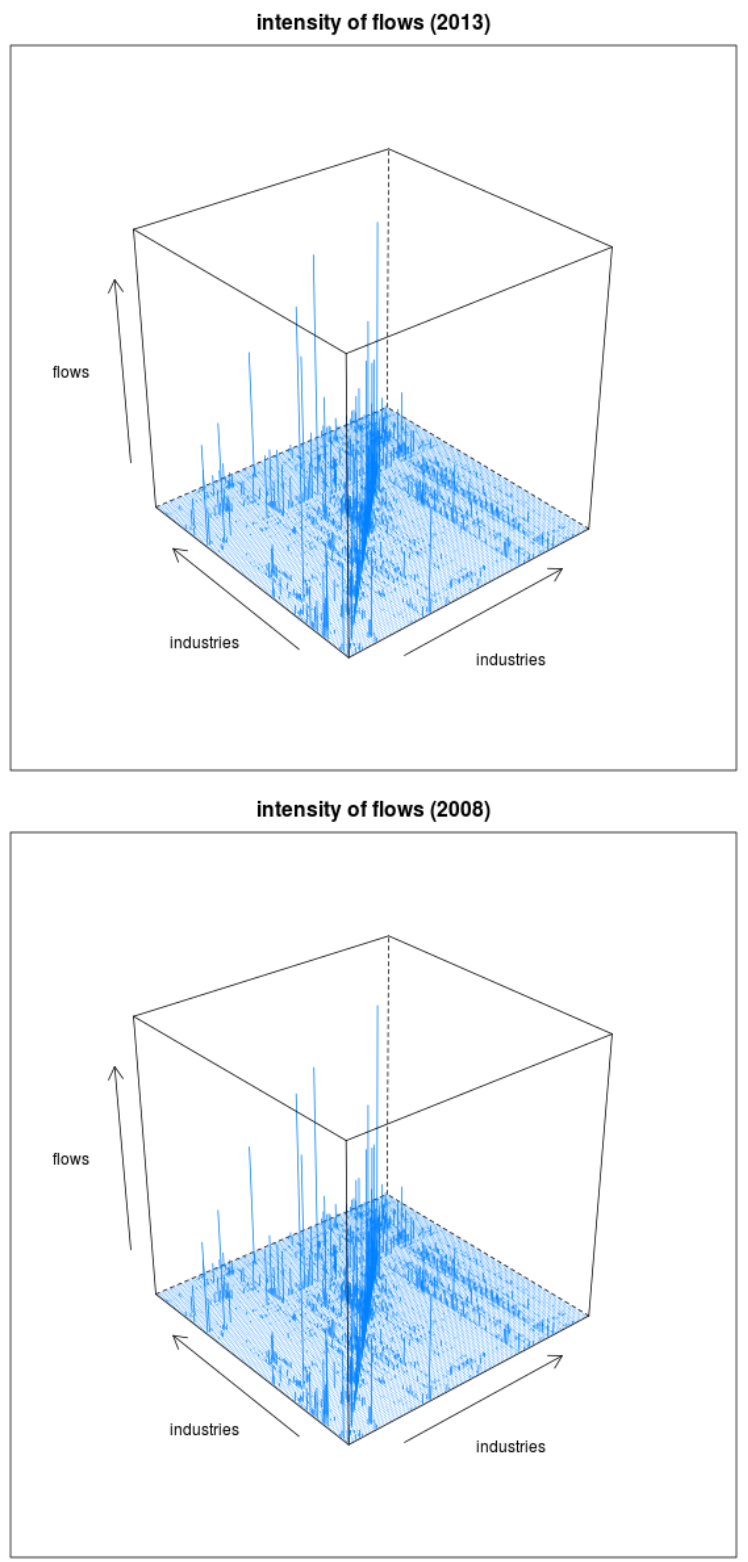



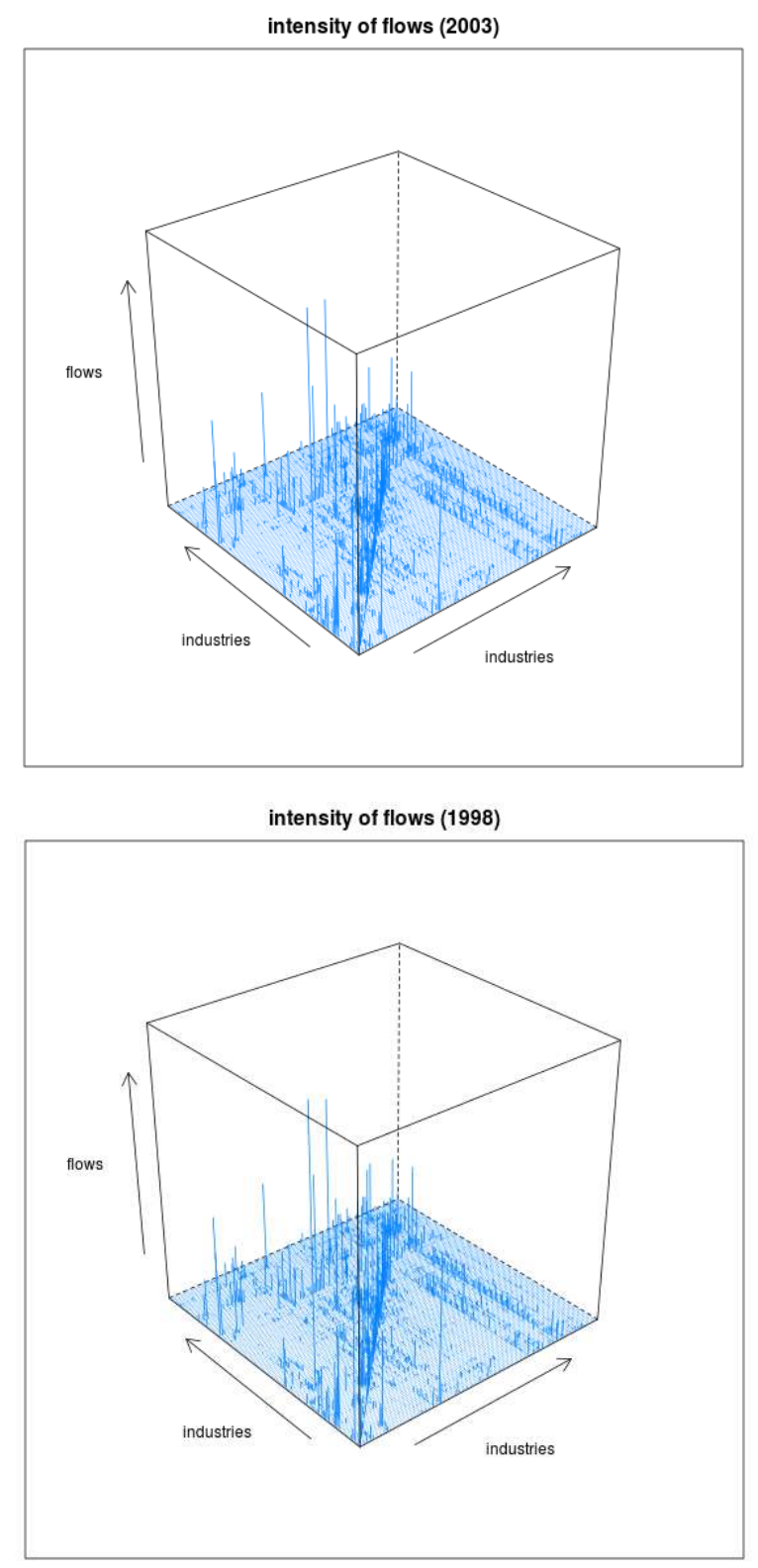

Figure 3. Flows among industries based on input-output table

As the figure 3 shows, although the input-output network generally is a complete network in which any pair of nodes is connected because the technical coefficients in the input-output table are positive normally, the whole network will be sparse if a suitable household of product flows is set. Flows are concentrated on some minority points, and also concentrated on the diagonal line obviously. That is to say, there is a clear feature of a country's economy which the self-inputs of industries are important and high weight edges in the networks, in other words, the self-loop in the networks are normal and significant. And the obvious high point in the picture shows that the flows is concentrated in fewer sectors. The four sub-figures in Figure 3 show some differences on the high points, and these will be analyzed in the following sections.

\subsection{Node Centrality Analysis}

Figure 4 and figure 5 shows the kernel density distribution of node strength centralities of CION (generated with the same bandwidth) based on technical coefficient matrix and normalized by relative value after 1990 respectively. Here we just focus on the intermediate nodes, and network's model built only including intermediate nodes. Figure 4 shows that the time duration before 2000 and after 2010 the distribution curves are flatter and wider than these years from 2001 to 2009 (the curves are more sharp and narrow). On the whole the density curves have the highest narrowest peak in 2003 approximately, and after that lowing and widening year by year. Because of the differences of output scale between industries, the technical coefficient cannot be used to compare with in timeline directly. However, figure 5 also shows similar features which the distribution curve tended to be flat and wide during last recent years (from 2009 to 2013), and they are almost overlapping. These means that the more balance of China economy in recently years near 2013 and earlier years in 1990s than 2003.

Kernel Density of vertex strength (with technical coefficient matrix)

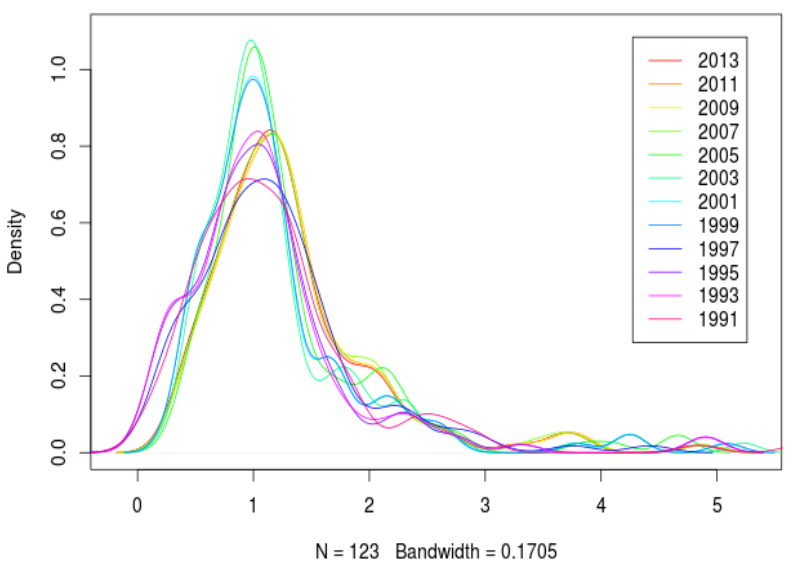

Figure 4. Kernel density distribution of node strength centralities of CION after 1990 (edge-weighted with technical coefficient)

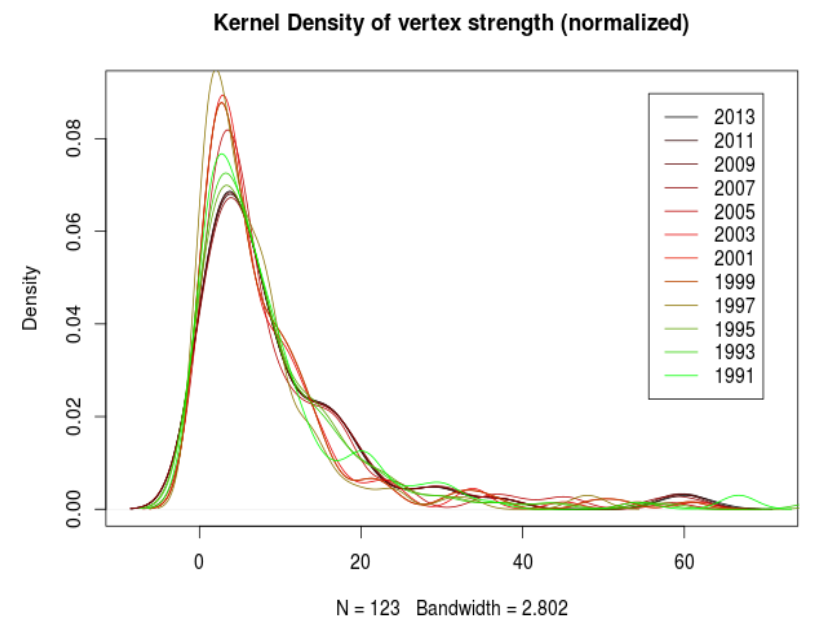

Figure 5. Kernel density distribution of node strength centralities of CION after 1990 (edge-weighted with normalized by relative value) 
Even curves illustrate that during those time period the total output of input-output table present a state of equilibrium among industries, i.e., the small-scale industries are more various, and the figure also shows that there is a small peak level at the high part of $\mathrm{x}$-axis. This small wave represents that there are some the large-scale industries which are the pillars of the economy which have a large-scale outputs. These phenomena stand for that during recent years China economy became more balanced and the increase of national economy caused by various industries instead of fewer industries.

The kernel density curves just present a rough description of industries distribution. To analyze the structure of node distribution, industries are ranked by the strength centralities. Table 2 shows the rank changes of industries from 1990 to 2013 which are at the top 10 positions in 2013. To avoid overcrowded columns in the table, we just list the ranks every other year.

Figure 6 exhibits more clearly the tendency of ranking of top 10 strength centralities from 1990 to 2013 which listed in table 2. Since 1990 most of the time construction had been in the top place with highest strength centralities, and this shows that construction had been one of the supporting industries in China economy, even if it was not in the official list of the dominant industries by Chinese government before 2000. Furthermore, since 1993 construction only lost its first place in the financial crisis started from Southeast Asia in 1997 and global economic crisis in 2008.

Table 2. Strength centralities rankings from 1991 to 2013 which are top 10 in 2013

\begin{tabular}{|c|c|c|c|c|c|c|c|c|c|c|c|c|}
\hline & 2013 & 2011 & 2009 & 2007 & 2005 & 2003 & 2001 & 1999 & 1997 & 1995 & 1993 & 1991 \\
\hline Construction & 1 & 2 & 2 & 3 & 1 & 1 & 1 & 1 & 2 & 1 & 1 & 3 \\
\hline Electricity and steam production and supply & 2 & 1 & 1 & 1 & 2 & 4 & 4 & 4 & 8 & 6 & 6 & 15 \\
\hline Steel-processing & 3 & 3 & 3 & 2 & 5 & 5 & 6 & 6 & 7 & 4 & 4 & 4 \\
\hline Petroleum refining & 4 & 4 & 4 & 4 & 6 & 6 & 5 & 5 & 9 & 19 & 19 & 16 \\
\hline Wholesale and retail trade & 5 & 5 & 5 & 5 & 3 & 2 & 2 & 2 & 4 & 3 & 3 & 2 \\
\hline Crop cultivation & 6 & 6 & 6 & 6 & 4 & 3 & 3 & 3 & 1 & 2 & 2 & 1 \\
\hline Other general industrial machinery & 7 & 7 & 7 & 7 & 8 & 10 & 10 & 10 & 16 & 8 & 8 & 7 \\
\hline Metal products & 8 & 8 & 8 & 8 & 9 & 9 & 9 & 9 & 5 & 5 & 5 & 5 \\
\hline Cotton textiles & 9 & 9 & 9 & 9 & 7 & 7 & 7 & 7 & 3 & 7 & 7 & 8 \\
\hline Other electric machinery and equipment & 10 & 10 & 10 & 10 & 10 & 11 & 11 & 11 & 10 & 13 & 13 & 20 \\
\hline
\end{tabular}

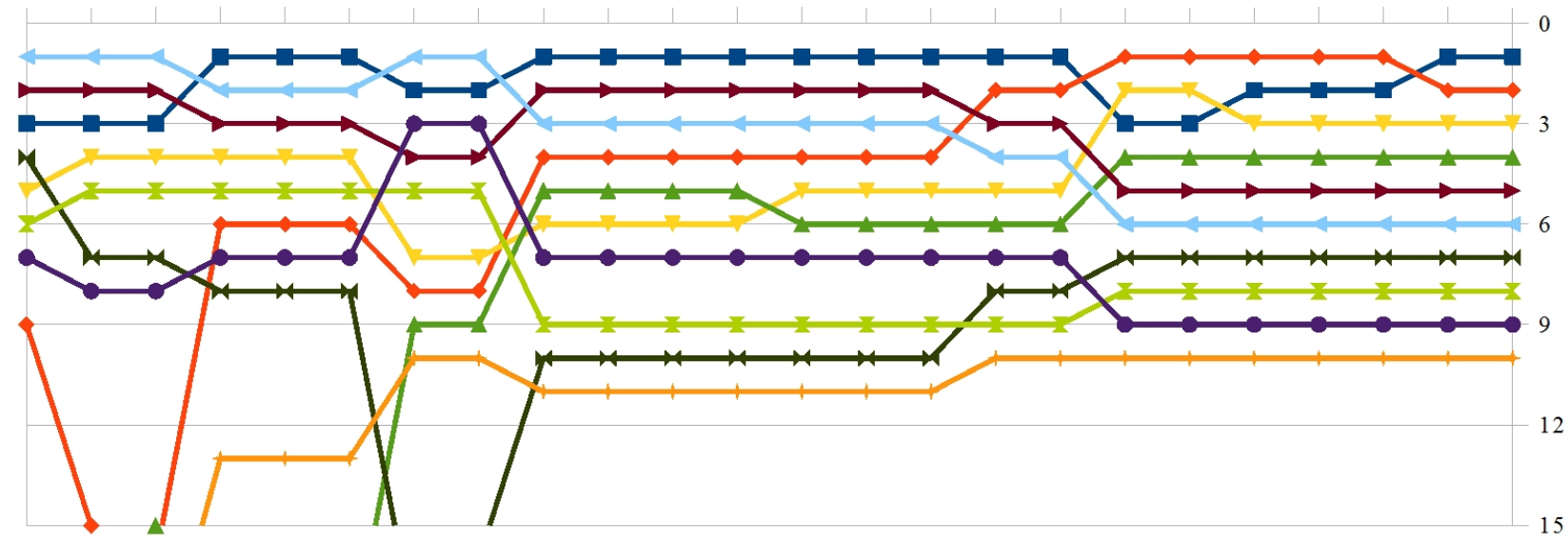

\section{6 9
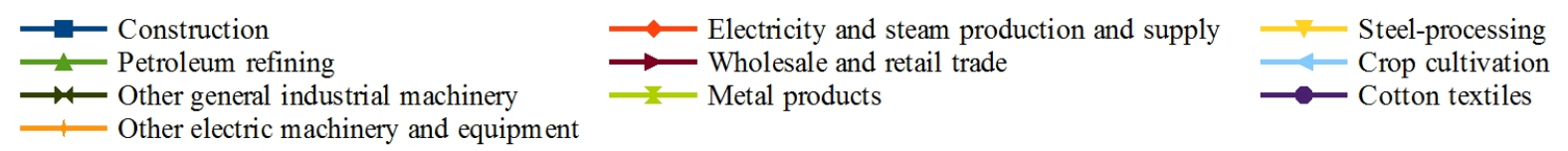

Figure 6. Tendency of 2013 top industries during 1990 to 2013 
During last decade electricity and steam production and supply came to the top 2 place since 2005 , and that the ranking of this industry had been growing steadily since 1992, and this exposed that the demand for electricity augmented continuously over time. In the list steel-processing and metal products are two industries closely related to construction.

Another noticeable industry is crop cultivation, which was ranked at first place in 1997, and it also stayed at top 3 place before 2005 . That is to say, crop cultivation was a large-scale industry which outputs were great in national economy. We also found that since 1997, the status of crop cultivation in the national economy was still at the forefront but it was indeed declining.

According to the structure of input-output table, the outputs of each industry can be decomposed to intermediate output and final output (including exports). Table 3 shows the structure of in-strength and out-strength centralities of top 10 industries of 2013 from 1991 to 2013.

However, the out-strength centrality of industry construction ranked far behind its in-strength in the intermediate networks. For example, its out-strength centrality ranked 43 while its in-strength centrality was at first place in 2013. By contrast the out-strength of intermediate nodes is calculated by the summary of domestic outputs except final demands. Therefore, construction is a non-primary input industry which the main outputs are final demands and exports to other countries. In general, table 3 shows that most of top 10 industries except construction are balanced between input and output.

As yet our analysis focus on the networks including intermediate nodes in input-output table. To explore the specificity of industrial outputs next we establish the extend networks including a node of domestic final demand. Table 4 shows the intermediate node strength centralities rankings of networks including domestic final demand in 2013. According to the table 4, in 2013 construction still ranked the first place in strength centralities in the extend networks. In contrast to the out-strength centrality in intermediate networks (not including the final demand node), the main outputs of construction are final demands instead of these as the inputs of other industries, which mean this industry closing to final demand. We will discuss this phenomena in detail in the next section by the index distance to final demand.

Furthermore, in table 4 out-strength centrality of node construction is almost twice as the second place, electricity and steam production and supply. This is in conformity with the policy which construction was listed as an important pillar industry supported by government since the end of last century. Even before this policy construction still one of the important industries ranked in top place. Whereas the in-strength centrality of construction also be at double of the second industry, which can be explained that it pull a lot of industries in developing.

Table 3. In- and out-strength from 1991 to 2013 which are top 10 in 2013

\begin{tabular}{|c|c|c|c|c|c|c|c|c|c|c|c|c|c|c|c|c|}
\hline & \multicolumn{8}{|c|}{ In-strength } & \multicolumn{8}{|c|}{ Out-strength } \\
\hline & 2013 & 2010 & 2007 & 2004 & 2001 & 1998 & 1994 & 1991 & 2013 & 2010 & 2007 & 2004 & 2001 & 1998 & 1994 & 1991 \\
\hline Construction & 1 & 1 & 1 & 1 & 1 & 1 & 1 & 1 & 43 & 41 & 41 & 33 & 34 & 33 & 33 & 39 \\
\hline $\begin{array}{l}\text { Electricity and steam production } \\
\text { and supply }\end{array}$ & 3 & 3 & 3 & 8 & 8 & 7 & 13 & 26 & 1 & 1 & 1 & 3 & 3 & 3 & 4 & 9 \\
\hline Steel-processing & 2 & 2 & 2 & 5 & 9 & 8 & 5 & 7 & 2 & 2 & 2 & 4 & 4 & 4 & 3 & 3 \\
\hline Petroleum refining & 4 & 4 & 4 & 4 & 4 & 4 & 29 & 19 & 5 & 5 & 5 & 5 & 5 & 5 & 15 & 12 \\
\hline Wholes & 11 & 10 & 10 & 2 & 2 & 2 & 3 & 2 & 3 & 3 & 3 & 1 & 1 & 1 & 2 & 2 \\
\hline Crop cultivation & 14 & 14 & 14 & 3 & 3 & 3 & 2 & 3 & 4 & 4 & 4 & 2 & 2 & 2 & 1 & 1 \\
\hline Other general industrial $\mathrm{r}$ & 6 & 6 & 7 & 12 & 13 & 13 & 11 & 9 & 6 & 6 & 6 & 8 & 9 & 9 & 7 & 7 \\
\hline Metal products & 5 & 5 & 5 & 9 & 11 & 11 & 4 & 6 & 7 & 7 & 8 & 10 & 11 & 11 & 5 & 5 \\
\hline Cotton textiles & 9 & 9 & 9 & 10 & 5 & 5 & 10 & 11 & 8 & 8 & 7 & 6 & 6 & 6 & 6 & 4 \\
\hline $\begin{array}{l}\text { Other electric machinery and } \\
\text { equipment }\end{array}$ & 8 & 8 & 8 & 11 & 10 & 10 & 15 & 22 & 11 & 11 & 11 & 14 & 12 & 12 & 12 & 18 \\
\hline
\end{tabular}

Table 4. Comparison of in-strength and out-strength with intermediate matrix and final demand included of nodes which are top in 2013

\begin{tabular}{lrrr} 
Year: 2013 & in strength & $\begin{array}{c}\text { out strength of } \\
\text { intermediate matrix }\end{array}$ & $\begin{array}{l}\text { out strength (final } \\
\text { demand included) }\end{array}$ \\
\hline Construction & 1497.17 & 110.51 & 2101.81 \\
Electricity and steam production and supply & 651.60 & 888.51 & 962.19 \\
Wholesale and retail trade & 306.20 & 624.61 & 844.15 \\
Steel-processing & 670.10 & 838.73 & 840.81 \\
Crop cultivation & 247.96 & 546.56 & 840.35 \\
Public administration and other sectors & 240.72 & 0.00 & 592.77 \\
Petroleum refining & 435.61 & 531.60 & 537.78 \\
Livestock and livestock products & 227.61 & 181.77 & 476.75 \\
Finance & 128.99 & 362.39 & 445.14 \\
Real estate & 73.04 & 113.84 & 433.00 \\
Metal products & 373.10 & 387.06 & 429.23 \\
\hline
\end{tabular}


Next exports and imports are included into our input-output networks, i.e., those start nodes and end nodes in figure 1 are involved into our model. According to the features of input-output table, if all start nodes and end nodes are included, the inputs are equal to the outputs and each node except the start nodes and end nodes are balanced between inputs and outputs. Table 5 shows the total outputs of top 20 commodities (industries) in the networks which including exports and imports in 2013 and 2012, which exhibit an overview of strength centralities of the networks. Start nodes include primary inputs and imports from other countries, and end nodes include final demand and exports to other countries.

From table 5 intermediate node construction still ranks the first place except for the start nodes and end nodes, and electricity and steam production and supply, wholesale and retail trade, crop cultivation etc. those industries rank high in the list. These results are similar as the results of sub-networks not including exports and imports. Compare to the outputs in table 4 , the list in table 5 shows that the exports of these industries contribute small, and the main outputs are in domestic. The reason is that we can easily find out that since China is a developing country with a large population, most of the output of basic industries like electricity and steam production and supply, wholesale and retail trade, crop cultivation that meet national life are consumed domestically.

\subsection{Analysis of Centrality-based Measures}

Next we excavate the deriving measures from strength centrality containing distance to final demand, import penetration and international outsourcing. Note that there are some negative data in Eora database, therefore, these numbers are ignored in our analysis, because negative distance to final demand is meaningless, and the same as import penetration and international outsourcing.

Table 6 list the measures of distance to final demand, import penetration, and international outsourcing in 2013 which industries ranked top 10 in out-strength centralities.

Table 5. Strength of top nodes of CION which inputs and outputs included in 2012 and 2013

\begin{tabular}{c|l|r|l|r}
\hline & Commodity & 2013 & Commodity & 2012 \\
\hline 1 & Compensation of employees D.1 & 3923.0 & Compensation of employees D.1 & 3417.1 \\
2 & Taxes on production D.29 & 2309.5 & Taxes on production D.29 & 2021.8 \\
3 & Construction & 2109.3 & Construction & 1873.8 \\
4 & Consumption of fixed capital K.1 & 1836.7 & Consumption of fixed capital K.1 & 1607.1 \\
5 & Electricity and steam production and supply & 962.7 & Electricity and steam production and supply & 860.2 \\
6 & Wholesale and retail trade & 939.3 & Wholesale and retail trade & 838.2 \\
7 & Net operating surplus B.2n & 901.8 & Net operating surplus B.2n & 787.8 \\
8 & Crop cultivation & 864.9 & Crop cultivation & 768.5 \\
9 & Steel-processing & 848.5 & Steel-processing & 759.7 \\
10 & Public administration and other sectors & 594.3 & Petroleum refining & 497.4 \\
11 & Petroleum refining & 555.3 & Public administration and other sectors & 496.0 \\
12 & Other general industrial machinery & 518.2 & Other general industrial machinery & 464.9 \\
13 & Metal products & 508.7 & Metal products & 458.1 \\
14 & Communication equipment & 483.5 & Communication equipment & 439.6 \\
15 & Livestock and livestock products & 479.6 & Livestock and livestock products & 426.8 \\
16 & Finance & 453.8 & Other electric machinery and equipment & 403.1 \\
17 & Other electric machinery and equipment & 446.1 & Finance & 403.0 \\
18 & Real estate & 439.5 & Real estate & 388.9 \\
19 & Educational services & 429.0 & Cotton textiles \\
20 & Other special industrial equipment & 422.4 & Other special industrial equipment & 379.0 \\
\hline
\end{tabular}

Table 6. Centrality-based measures in 2013

\begin{tabular}{lrrr}
\hline Year: 2013 & $\begin{array}{c}\text { distance to final } \\
\text { demand }\end{array}$ & $\begin{array}{c}\text { import } \\
\text { penetration }\end{array}$ & $\begin{array}{c}\text { international } \\
\text { outsourcing }\end{array}$ \\
\hline Construction & 0.055 & 0.573 & 0.076 \\
Electricity and steam production and supply & 12.058 & 0.027 & 0.027 \\
Steel-processing & 403.726 & 0.052 & 0.058 \\
Petroleum refining & 85.977 & 0.084 & 0.096 \\
Wholesale and retail trade & 2.845 & 0.044 & 0.032 \\
Crop cultivation & 1.860 & 0.030 & 0.020 \\
Other general industrial machinery & 5.405 & 0.095 & 0.089 \\
Metal products & 9.180 & 0.098 & 0.091 \\
Cotton textiles & 24.194 & 0.041 & 0.040 \\
Other electric machinery and equipment & 14.253 & 0.099 & 0.084 \\
\hline
\end{tabular}


Among these nodes steel-processing is far away from final demand, yet construction is near to the final demand, and its import penetration is much higher than others. Furthermore, their rates of international outsourcing are in a low level which illustrate that most of its upstream inputs came from domestic industries, except for petroleum refining which international outsourcing is at least relatively high than others.

Table 7 list the ranks of distance to final demand from 2004 to 2013 of the top 10 industries nearest to final demand in 2013. Construction was on the third place in distance in 2013. Public administration and other sectors is the industry nearest to final demand, and almost no distance to final demand, which means this sector export nothing to others, and actually it is the final demand for other inputs or industries. Table 7 also shows that environmental resources and public infrastructure was getting closer to the final demand during last decade, and real estate also presents the same tendency.

Figure 7 shows the density distribution in 2013 in distance to final demand. To make the curve readable we ignore that nodes which are far away from final demand, and if the distance to final demand is larger than 100 its value was limited to be 100 , so that the horizontal axis in the figure is limited to be a readable range. The curve shows that there are two wave peaks that the large one locate at the beginning and the low one locate the high value where the tail of curve is. The low wave peak means that there are some points which are far away from final demand.

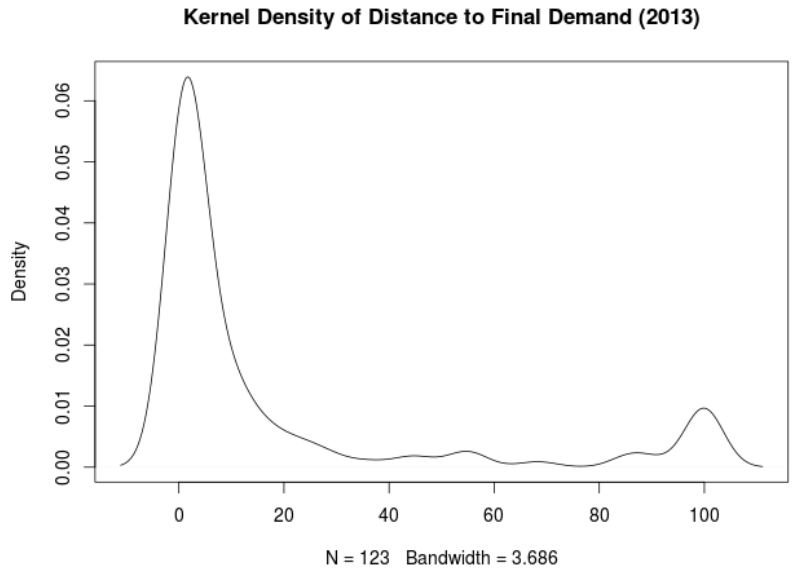

Figure 7. Kernel density distribution of distance to final demand in 2013

Import penetration. Table 8 shows the 2013 top 12 industries in the import penetration from 2004 to 2013 except for the re-export \& re-import node. Astonishingly public administration and other sectors rank the first place and its import penetration rate nearly reach $100 \%$, and sports rank the second place and has more than ninety percent rate. Construction also appear in this list and higher than $55 \%$, which is required in-depth analysis. A group of industries relative to electronic technology, electronic computer, other computer devices, electronic appliances, other electronic and communication equipment, are highly dependent on import. The import penetration rates of scientific research and educational services are in the forefront of the list.

Table 7. Distance to final demand from 2004 to 2013

\begin{tabular}{|c|c|c|c|c|c|c|c|c|c|c|}
\hline Year & 2013 & 2012 & 2011 & 2010 & 2009 & 2008 & 2007 & 2006 & 2005 & 2004 \\
\hline $\begin{array}{l}\text { Public administration and other } \\
\text { sectors }\end{array}$ & 0.000 & 0.000 & 0.000 & 0.000 & 0.000 & 0.000 & 0.000 & 0.000 & 0.000 & 0.000 \\
\hline Sports & 0.002 & 0.002 & 0.003 & 0.003 & 0.003 & 0.003 & 0.002 & 0.000 & 0.000 & 0.000 \\
\hline Construction & 0.055 & 0.055 & 0.061 & 0.063 & 0.064 & 0.068 & 0.069 & 0.073 & 0.071 & 0.067 \\
\hline Educational services & 0.082 & 0.089 & 0.097 & 0.095 & 0.091 & 0.099 & 0.098 & 0.093 & 0.082 & 0.072 \\
\hline Social welfare & 0.099 & 0.115 & 0.126 & 0.121 & 0.117 & 0.128 & 0.125 & 0.093 & 0.072 & 0.041 \\
\hline Health & 0.191 & 0.203 & 0.219 & 0.216 & 0.210 & 0.223 & 0.222 & 0.131 & 0.113 & 0.091 \\
\hline Scientific research & 0.289 & 0.328 & 0.351 & 0.339 & 0.329 & 0.357 & 0.370 & 0.712 & 0.623 & 0.300 \\
\hline $\begin{array}{l}\text { Environmental resources and public } \\
\text { infrastructure }\end{array}$ & & 0.351 & & & & 0.384 & & & 0.491 & 0.465 \\
\hline Other f & 0.343 & 0.345 & 0.370 & 0.374 & 0.369 & 0.371 & 0.367 & 0.248 & 0.234 & 0.206 \\
\hline Domestic public transport & & 0.373 & & & 0.387 & 0.407 & 0.409 & 0.424 & 0.396 & 0.312 \\
\hline Real estate & 0.357 & 0.349 & 0.374 & 0.381 & 0.379 & 0.393 & 0.392 & 0.436 & 0.417 & 0.406 \\
\hline $\begin{array}{l}\text { Toys, sporting and athletic and } \\
\text { recreation products }\end{array}$ & 0.424 & 0.428 & 0.451 & 0.458 & 0.456 & 0.451 & 0.447 & 0.641 & 0.609 & 0.439 \\
\hline
\end{tabular}


Table 8. Import penetration rankings from 2004 to 2013 which are top 12 in 2013

\begin{tabular}{|c|c|c|c|c|c|c|c|c|c|c|}
\hline & 2013 & 2012 & 2011 & 2010 & 2009 & 2008 & 2007 & 2006 & 2005 & 2004 \\
\hline Public administration and other sectors & 1.000 & 1.000 & 1.000 & 1.000 & 1.000 & 1.000 & 1.000 & 1.000 & 1.000 & 1.000 \\
\hline Sports & 0.945 & 0.949 & 0.928 & 0.926 & 0.907 & 0.940 & 0.979 & 0.999 & 0.999 & 0.999 \\
\hline Construction & 0.573 & 0.597 & 0.576 & 0.551 & 0.520 & 0.552 & 0.577 & 0.536 & 0.517 & 0.552 \\
\hline Cultural and office equipment & 0.498 & 0.522 & 0.518 & 0.500 & 0.447 & 0.552 & 0.661 & 0.746 & 0.731 & 0.769 \\
\hline $\begin{array}{l}\text { Toys, sporting and athletic and recreation } \\
\text { products }\end{array}$ & 0.492 & 0.519 & 0.513 & 0.494 & 0.440 & 0.532 & 0.563 & 0.499 & 0.466 & 0.575 \\
\hline Electronic computer & 0.409 & 0.424 & 0.415 & 0.401 & 0.361 & 0.415 & 0.440 & 0.455 & 0.479 & 0.523 \\
\hline Other computer devices & 0.376 & 0.393 & 0.393 & 0.379 & 0.336 & 0.402 & 0.430 & 0.449 & 0.483 & 0.502 \\
\hline Electronic appliances & 0.358 & 0.376 & 0.370 & 0.356 & 0.316 & 0.373 & 0.391 & 0.422 & 0.435 & 0.482 \\
\hline $\begin{array}{l}\text { Other electronic and communication } \\
\text { equipment }\end{array}$ & 0.298 & 0.320 & 0.319 & 0.301 & 0.255 & 0.329 & 0.362 & 0.386 & 0.392 & 0.508 \\
\hline Leather, furs, down and related products & 0.296 & 0.320 & 0.311 & 0.293 & 0.251 & 0.317 & 0.374 & 0.403 & 0.331 & 0.332 \\
\hline Scientific research & 0.288 & 0.295 & 0.273 & 0.263 & 0.228 & 0.273 & 0.332 & 0.161 & 0.176 & 0.328 \\
\hline Educational services & 0.278 & 0.306 & 0.242 & 0.230 & 0.207 & 0.246 & 0.246 & 0.263 & 0.265 & 0.303 \\
\hline
\end{tabular}

The density distribution of import penetration became more and sharper during last decades, which means some industries tended toward independent of imports. This kind of tendency can be derived from figure 8 , which exhibits some kernel density curves of import penetration since 1990.

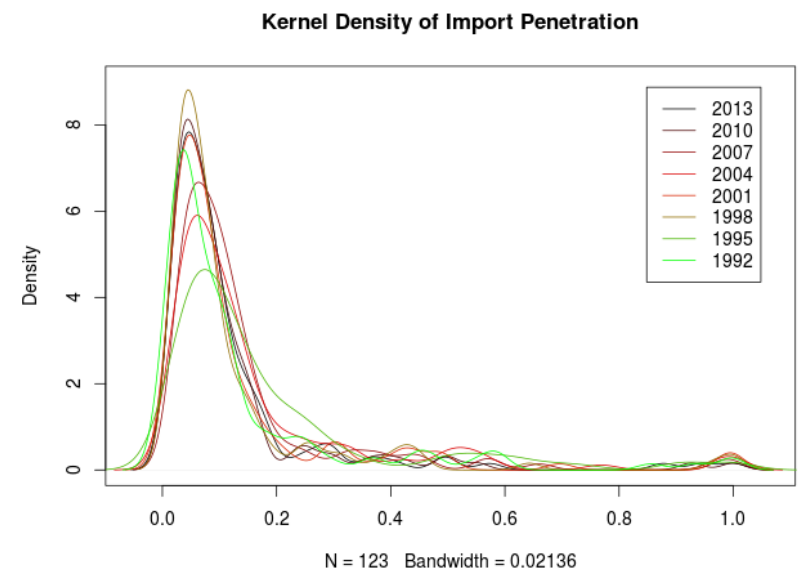

Figure 8. Kernel density distribution of import penetration after 1990

International outsourcing. This rate displays the foreign dependency of industries. Table 9 list top 12 industries in international outsourcing except for the node re-import \& re-export. These industries mainly focus on computer, electronics, and chemical industry, and in accordance with the current reality of China, which products of high-tech electronics are more dependent on international outsourcing. The international outsourcing rate of culture and office equipment is high and rank the second place, which exhibits that nowadays in China there are so many culture products such as films, music products, TV shows, etc., imported from outside.

This table also display a phenomenon that only the top four industries have a high rate in international outsourcing, and from the five place there is an obvious decrease in this rate. Therefore, the whole situation of China economy looks in a well status from this perspective.

\subsection{Clustering Coefficient}

Cerina et al. (2015) concluded that clustering coefficient is positively correlated with the intermediate transactions over time, or the increasingly integrated production chains tend to make the networks more clustered and more assortative. Table 10 lists the 2013 top 10 industries in clustering coefficient from 2004 to 2013. During these years most of industries in the table kept steady in clustering coefficient, and there are four industries, i.e., health services, wearing apparel, other food products, other textiles not elsewhere classified, which are decreasing steadily in this indicator, while social welfare showed fluctuation changes.

Except for construction most of industries listed in the top strength centrality rank list have not appeared in this list. So to say construction shows its influence in almost all kinds of measures in our studies. Public administration and other sectors is prominent in clustering coefficient, and the following is sports which almost to the same level. Furthermore, seven of these industries also appear in the list of distance to final demand, and three of them appear in the list of import penetration. By contrast, the more one industry is near to the final demand, the more influence it is. 
Table 9. International outsourcing rankings from 2004 to 2013 which are top 12 in 2013

\begin{tabular}{|c|c|c|c|c|c|c|c|c|c|c|}
\hline & 2013 & 2012 & 2011 & 2010 & 2009 & 2008 & 2007 & 2006 & 2005 & 2004 \\
\hline Other computer devices & 0.516 & 0.571 & 0.570 & 0.529 & 0.421 & 0.529 & 0.613 & 0.675 & 0.947 & 0.906 \\
\hline Cultural and office equipment & 0.439 & 0.480 & 0.481 & 0.450 & 0.368 & 0.424 & 0.378 & 0.306 & 0.298 & 0.356 \\
\hline Electronic computer & 0.394 & 0.434 & 0.437 & 0.406 & 0.327 & 0.422 & 0.484 & 0.520 & 0.670 & 0.672 \\
\hline Electronic appliances & 0.384 & 0.425 & 0.424 & 0.396 & 0.317 & 0.410 & 0.455 & 0.522 & 0.531 & 0.671 \\
\hline $\begin{array}{l}\text { Other electronic and communication } \\
\text { equipment }\end{array}$ & 0.194 & 0.210 & 0.208 & 0.196 & 0.162 & 0.196 & 0.227 & 0.237 & 0.241 & 0.308 \\
\hline Electronic element and device & 0.158 & 0.173 & 0.171 & 0.160 & 0.130 & 0.164 & 0.183 & 0.219 & 0.368 & 0.302 \\
\hline Plastic products & 0.131 & 0.142 & 0.142 & 0.130 & 0.107 & 0.136 & 0.146 & 0.151 & 0.149 & 0.160 \\
\hline Sawmills and fibreboard & 0.128 & 0.140 & 0.139 & 0.127 & 0.105 & 0.132 & 0.179 & 0.169 & 0.196 & 0.175 \\
\hline Chemical pesticides & 0.127 & 0.138 & 0.136 & 0.125 & 0.101 & 0.131 & 0.138 & 0.130 & 0.119 & 0.151 \\
\hline Communication equipment & 0.126 & 0.137 & 0.137 & 0.128 & 0.106 & 0.129 & 0.159 & 0.171 & 0.169 & 0.231 \\
\hline Synthetic chemicals & 0.117 & 0.127 & 0.125 & 0.114 & 0.094 & 0.121 & 0.126 & 0.128 & 0.158 & 0.144 \\
\hline Computing services and software & 0.114 & 0.125 & 0.124 & 0.115 & 0.095 & 0.122 & 0.132 & 0.121 & 0.112 & 0.132 \\
\hline
\end{tabular}

Table 10. Top 10 industries in clustering coefficient from 2004 to 2013

\begin{tabular}{|c|c|c|c|c|c|c|c|c|c|c|}
\hline & 2013 & 2012 & 2011 & 2010 & 2009 & 2008 & 2007 & 2006 & 2005 & 2004 \\
\hline Public administration and other sectors & 1.506 & 1.506 & 1.506 & 1.506 & 1.506 & 1.506 & 1.506 & 1.506 & 1.506 & 1.506 \\
\hline Sports & 1.503 & 1.502 & 1.502 & 1.502 & 1.502 & 1.502 & 1.503 & 1.506 & 1.506 & 1.506 \\
\hline Construction & 1.437 & 1.437 & 1.431 & 1.429 & 1.429 & 1.422 & 1.420 & 1.416 & 1.419 & 1.422 \\
\hline $\begin{array}{l}\text { Toys, sporting and athletic and } \\
\text { recreation products }\end{array}$ & 1.386 & 1.391 & 1.390 & 1.391 & 1.387 & 1.414 & 1.427 & 1.402 & 1.405 & 1.419 \\
\hline Social welfare & 1.360 & 1.341 & 1.334 & 1.339 & 1.343 & 1.329 & 1.336 & 1.312 & 1.359 & 1.388 \\
\hline Educational services & 1.346 & 1.335 & 1.327 & 1.332 & 1.338 & 1.322 & 1.323 & 1.314 & 1.341 & 1.340 \\
\hline Health services & 1.302 & 1.293 & 1.285 & 1.288 & 1.293 & 1.280 & 1.281 & 1.320 & 1.356 & 1.353 \\
\hline Wearing appare1 & 1.299 & 1.306 & 1.303 & 1.301 & 1.294 & 1.337 & 1.361 & 1.377 & 1.379 & 1.377 \\
\hline Other food products & 1.268 & 1.267 & 1.261 & 1.260 & 1.261 & 1.264 & 1.265 & 1.311 & 1.322 & 1.329 \\
\hline Other textiles not eslseshere classified & 1.266 & 1.274 & 1.275 & 1.270 & 1.255 & 1.306 & 1.313 & 1.317 & 1.309 & 1.308 \\
\hline
\end{tabular}

The public administration and other sectors, sports, construction, etc., are identified as predominantly output producing industries during these years, and perform the steady trends. Whereas tops, sporting and athletic and recreation products, wearing apparel, other food products, and other textiles not elsewhere classified, these four industries perform the decrease trend during these years, and three other industries, social welfare, educational service, and health services express a smiling curve trend which falling first and then increasing. In addition, among the top main industries, only construction still list in this table, shows that construction perform very important for whatever aspects.

\section{Conclusions}

The aim of this paper was to contribute to a better understanding of developments and changes of China economy from the perspective of input-output networks between 1990 and 2013. Through choosing a network-based approach and combining this with input-output data we are able to analyze the changes and evolutions of centralities, which measured by strength centrality and clustering coefficient, and some extend measures based on centrality including import penetration, international outsourcing and distance to final demand.

Our findings show that the basic impression about input-output networks is that flows are concentrated on some minority points, and also concentrated on the diagonal line obviously, i.e., the self-loops in the networks are normal and significant. Future studies in this aspect can locate on the community detections which identify the modules and their hierarchical organization in the networks.

According to the analysis results on node centralities of China input-output networks, lower and wider peak of the curve of density strength centralities illustrate the more balance of China economy than at the beginning of this century. Moreover, construction has always been the pillar industry, and ranked first from 1998 to 2006 as well as after 2011 in the strength centrality list. Other important industries in the strength centrality list include electricity and steam production and supply, steel processing, petroleum refining, crop cultivation, wholesale and retail trade, etc.

Based on the analysis of strength-based measures, most of industries present a trend of first climbing and then falling after 2000. Among the largest industries only construction have been near to the final demands. Other industries near the final demand including public administration and other sectors, sports, education services, 
social welfare, and so on. The changes of distribution of import penetration are similar as the distance to final demand, which becoming flatter and lower since 1990 and then narrower and higher about after 2001. This trend means that after 2001 most of China industries decrease the dependencies of import from outside. Construction also is included in this list. Although industries relate to computer and electronic devices be top of the list, and are far more than others, their import penetration rates show the decline tendency year by year. The public administration and other sectors, sports, construction, etc., are identified as predominantly output producing industries during these years, and perform the steady trends. Furthermore, seven of these industries also appear in the list of distance to final demand, and three of them appear in the list of import penetration.

In summary, with the analysis of China input-output networks, we have an overview of China economy system and industrial structure. Future studies we will proceed next locate on the community detections to find the relationship between industries, and on modelling the input-output networks to discover the mechanism of evolution.

\section{REFERENCES}

[1] Barat, A., Barthelemy, M., Pastor-Satorras, R. \& Vespignani, A. (2004). The architecture of complex weighted networks. Proceedings of the National Academy of Sciences of the United States of America, 101 (11): 3747-3752, DOI:10.1073/pnas.0400087101

[2] Benedictis, L. D., Tajoli, L. (2011). The World Trade Network. The World Economy, DOI: 10.1111/j.1467-9701 .2011.01360.x
[3] Cerina, F., Zhu, Z., Chessa, Chessa, A. \& Riccaboni, M. (2015). World Input-Output Network. PLoS ONE, 10(7):e0134025. DOI 10.1371/journal.pone.0134025

[4] Duan, W.Q., (2011). Modelling the Evolution of National Economies Based on Input-Output Networks. Computational Economics, DOI 10.1007/s10614-011-9261 $-3$

[5] Falk, M., (2012). International Outsourcing and Productivity Growth. Reivew of Economics and Institutions, Vol.3, No.1, DOI 10.5202/rei.v3il.54

[6] Iapadre, P. L., \& Tajoli, L. (2014). Emerging countries and trade regionalization: a network analysis. Journal of Policy Modeling, 36S, S89-S110

[7] Lenzen, M., Kanemoto, K., Moran, D., \& Geschke, A., (2012). Mapping the Structure of the World Economy. Environmental Science \& Technology, 46(15), pp.8374-8381

[8] Lenzen, M., Moran, D., Kanemoto, K., \& Geschke, A., (2013). Building Eora: a Global Multi-Region Input-Output Database at High Country and Sector Resolution. Economic Systems Research, 25(1), pp.20-49, DOI:10.1080/0953531 4.2013.769938

[9] Maluck, J., \& Donner, R. V., (2015). A network of networks perspective on global trade. PLoS ONE, 10(7): e0133310. Doi: 10.1371journal.pone.0133310.

[10] Newman, M.E.J. (2003). The Structure and Function of Complex Networks. SIAM Review. 45:167-256

[11] Opsahl, T., Agneessens, F., \& Skvoretz, J., (2010). Node centrality in weighted networks: Generalizing degree and shortest paths. Social Networks, 32(3), pp.245-251, DOI: 10.1016/j.socnet.2010.03.006

[12] Schutz, M. H., \& Palan, N., (2016). Restructuring of the International clothing and textile trade network: the role of Italy and Portugal. Journal of Economic Structures, 5:16. DOI: $10.1186 / \mathrm{s} 40008-016-0046-7$ 